Este libro forma parte del acervo de la Biblioteca Jurídica Virtual del Instituto de Investigaciones Jurídicas de la UNAM

\title{
MATERNIDAD Y COVID-19
}

\author{
Raymundo Canales de la FUente
}

\begin{abstract}
SUMARIO: I. Introducción. II. Evolución de la salud materna antes del COVID-19. III. Crisis del COVID-19 en el embarazo. IV. Efectos en el feto y recién nacido del SARS-COV-2. V. Vacuna contra el SARS-CoV-2 en el embarazo. VI. Reflexiones finales. VII. Referencias.
\end{abstract}

\section{INTRODUGCIÓN}

La enfermedad llamada COVID-19, causada por un virus nuevo, el SARS$\mathrm{CoV}-2$, ha sorprendido a la humanidad a pesar de que es relativamente inocuo. Comparando la tasa de letalidad de la pandemia actual con otras enfermedades virales como la rabia o el ébola, que a pesar de ser tratadas en las mejores condiciones médicas se acercan al 100\%, el COVID-19 es poco letal (Wikipedia 2020). La mayoría de las personas que padecen la infección se recuperan rápidamente y sin secuelas, incluso hay una proporción muy grande - cuyas dimensiones incluso no se han ponderado por falta de herramientas - la padecen sin presentar siquiera síntomas. Ese segmento de la población parece estar constituida por los más jóvenes. Los niños y niñas, que raramente presentan las formas graves del padecimiento son extraordinariamente eficaces para contagiarla, y quienes se encuentran en el otro extremo de la vida, es decir los adultos mayores se encuentran en situación vulnerable para complicarse o morir en el curso del padecimiento. Es de señalarse en este panorama, que los científicos encargados de estos temas tienen muchos años advirtiéndole a la sociedad del riesgo inminente de una pandemia causada por un virus respiratorio (Webster, 2018), de fácil contagio, que podría causar estragos a la humanidad, sin obtener siquiera respuesta de los encargados de la política en ninguna parte del orbe. En este sentido se parece al tema del medio ambiente acerca del cual sobran advertencias, pero en concreto nadie hace caso de las mismas. También se parece en el sentido de que finalmente 
Este libro forma parte del acervo de la Biblioteca Jurídica Virtual del Instituto de Investigaciones Jurídicas de la UNAM

la sociedad solo responde frente a los riesgos económicos inmediatos, lo demás parece ser un discurso académico que no tiene impacto prácticamente en ningún ámbito. La atención a la salud no es ajena a la transformación social; el día de hoy la mayoría de las sociedades occidentales contemplan la atención a la salud pública no exactamente como un negocio, pero si como un gasto con la obligación de ser autosustentable, argumento francamente insostenible. No existe solución razonable para proponer un servicio público de salud que se pueda sostener a si mismo sin afectar a los enfermos. Europa, quizá una de las regiones del mundo más avanzada en el discurso de los derechos humanos, se encuentra enfrentando esta contradicción fundamental y muchos de sus sistemas sanitarios se vieron rebasados por la actual pandemia en vista de que no existía infraestructura suficiente debido a criterios de "eficiencia económica". Nunca pensé contemplar un escenario que llevara al límite a sistemas sanitarios tan buenos como los de la Reino Unido o Francia. Por supuesto percibir esa crisis con un par de meses de antelación, dado que la infección los afectó previamente, nos causó un muy amargo sabor de boca sabiendo que nuestra región latinoamericana tiene sistemas de salud mucho más limitados, débiles e ineficientes comparados con aquella región. Si bien México tuvo un desarrollo de vanguardia en cuanto a la seguridad social, el día de hoy se encontraba, desde antes de la epidemia de COVID-19, en una crisis de financiamiento de sus instituciones sanitarias por razones que no voy a exponer aquí, pero que sin duda lo confrontan a una situación en extremo complicada. Todavía al inicio de la epidemia muchos médicos teníamos algunas expectativas relativas al posible comportamiento diferente del virus en virtud del clima y de una composición poblacional también diversa. No ocurrió así. El virus se asentó con pocas diferencias y nuestra ventaja de ser una población más joven, se vio mermada por la enorme prevalencia del sobrepeso y la obesidad como fenómeno social fuera de control. En este contexto, la salud materna se ubica como uno de los hilos más delgados del sistema; el embarazo, parto y puerperio, si bien ocurren en mujeres jóvenes, ya se encontraban en situación de alta vulnerabilidad porque las instituciones públicas no habían logrado un acuerdo fundamental y universal para atenderlas a todas por igual en un sistema eficiente. Con enorme tristeza contemplamos que México, como país, nunca pudo alcanzar la disminución en mortalidad materna planteada en los objetivos del milenio, básicamente por problemas de desorganización de toda la atención sanitaria. Teníamos un saldo pendiente grave al arribo del SARS-GoV-2; lo que provocó simplemente que se acentuara el problema. Adicionalmente las mujeres gestantes han sido presa también de la enorme prevalencia de obesidad, de tal magnitud que el día 
Este libro forma parte del acervo de la Biblioteca Jurídica Virtual del Instituto de Investigaciones Jurídicas de la UNAM

de hoy calculamos que quizá cerca del 20\% de ellas presentan diabetes gestacional (Dainelli et al., 2018) y el colmo es que no se busca sistemáticamente en el control prenatal.

\section{EVOLUCIÓN DE LA SALUD MATERNA ANTES DEL COVID-19}

La salud materna ha representado un reto a nivel mundial por muchas razones. Su conservación es una característica de sociedades que han avanzado en el combate a la pobreza, a la discriminación y a la preservación de los derechos sexuales y reproductivos de las mujeres. Las personas que hemos dedicado tiempo a la investigación en ese campo, frecuentemente la entendemos como un fenómeno multidimensional porque no solamente se trata de eficacia en la atención obstétrica sino de disponibilidad de muchos elementos como educación sexual y reproductiva desde los niveles elementales, acceso al aborto seguro, atención prenatal de calidad, atención del parto en lugares seguros y por personal calificado, disponibilidad de comunicaciones y transporte rápido, disponibilidad de sangre para transfusiones inmediatas, y un sinnúmero de elementos concomitantes que no resultan fáciles de articular de un plumazo, como pretenden siempre los políticos. Una forma triste pero eficaz de evaluar el comportamiento de un país es mediante la razón de muerte materna que significa el número de mujeres muertas durante el embarazo, parto o puerperio dividido por cine mil nacidos vivos. El planeta presenta enormes disparidades en este indicador, México se encuentra en una posición intermedia (figura 1) en el concierto mundial, pero no hemos bajado la cifra en la magnitud que quisiéramos. Las diferencias con países desarrollados son penosas.

Si nos comparamos con países como Francia o el Reino Unido que reportan cifras de entre 7 y 8 quedamos muy mal. Nuestras últimas cifras se encuentran por arriba de 30 muertes por 100 mil nacidos vivos, por supuesto es una diferencia abismal comparada con el África Sub-Sahariana pero varias veces mayor que la mayoría de los países europeos. Al cambio del milenio, hubo un acuerdo que México firmó y se comprometió a reducir para el año 2015, en tres cuartas partes la reportada en 1990. Simplemente no cumplimos. No fuimos capaces como sociedad avanzada de alcanzar la meta comprometida. En 1990 la cifra alcanzaba 89 por 100 mil nacidos vivos, por lo que en el 2015 debimos haber alcanzado cerca de 23, hecho que a la fecha no ha ocurrido... en el 2020. Muchas personas hemos trabajado desde multiplicidad de trincheras para lograr la deseada disminución de las terribles muertes maternas, que además debo mencionar, la inmensa mayo- 
Este libro forma parte del acervo de la Biblioteca Jurídica Virtual del Instituto de Investigaciones Jurídicas de la UNAM

\section{FIGURA $1^{*}$}

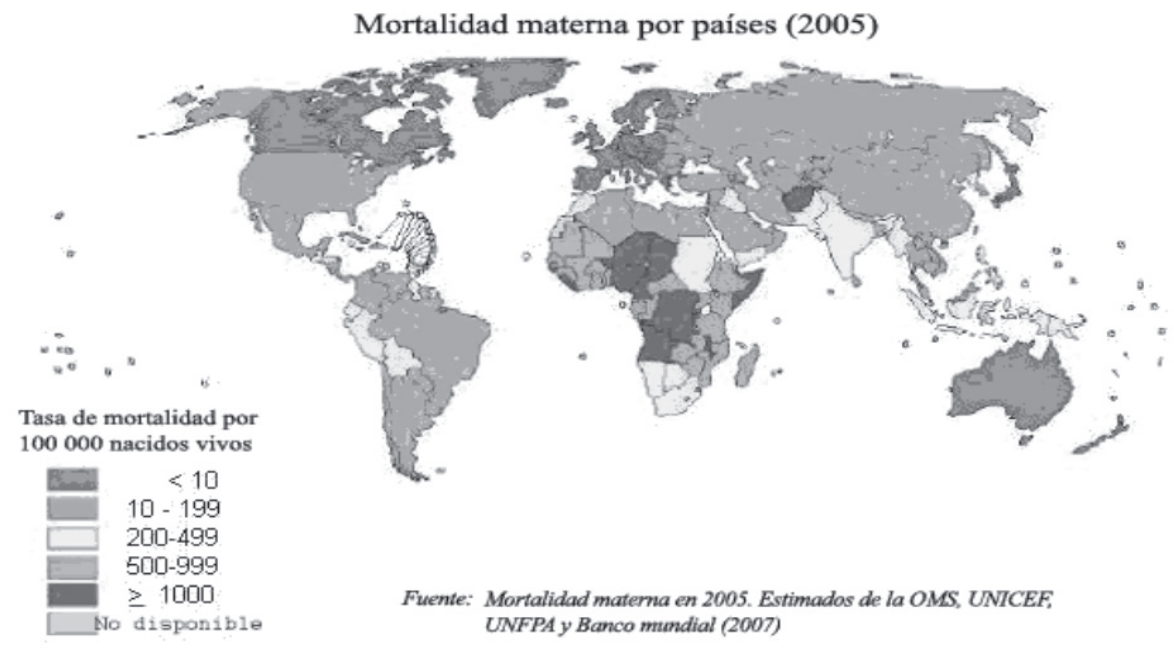

ría son prevenibles, lo que las diferencia de las muertes por enfermedades crónicas como el cáncer. Si bien es cierto que muchos tumores malignos hoy se pueden tratar e incluso curar especialmente en sus fases iniciales, existen todavía muchos por los que poco podemos hacer los médicos; eso provoca que la realidad de la muerte materna sea diametralmente diferente. El hecho de que cuantitativamente sean pocas comparadas con el cáncer, no lo hace menos grave. Prácticamente ninguna mujer debería morir en el acto de dar a luz a un vástago. Nuestra realidad poblacional y de política pública de los últimos 20 o 25 años, nos ha conducido además, como dije antes, a una "epidemia" silenciosa de obesidad que afecta por igual a las mujeres en edad reproductiva, y esas condiciones distan mucho de ser las mejores para cursar una gestación. La enorme prevalencia de sobrepeso en el embarazo tiene consecuencias graves como el incremento en la diabetes gestacional, la enfermedad hipertensiva y en general un pobre manejo de la sobrecarga que representa al organismo de las mujeres transitar a lo largo de una gestación. Por supuesto los esfuerzos que, como gobierno se han articulado han provocado una disminución paulatina en las muertes maternas, pero las resistencias de muchos segmentos de la sociedad han dificultado el progreso; cito como ejemplo claro la despenalización del aborto que previene muertes de mujeres embarazadas al ser atendidas en un ambiente sanitario adecuado.

* Aunque los datos de la figura son de 2005, esto es intrascendente para los fines de la gráfica: actualmente la mortalidad materna en México cabe entre 10 y 199. 
Este libro forma parte del acervo de la Biblioteca Jurídica Virtual del Instituto de Investigaciones Jurídicas de la UNAM

FIGURA 2

Tasa de mortalidad materna (muertes / 100.000 niños nacidos vivos)

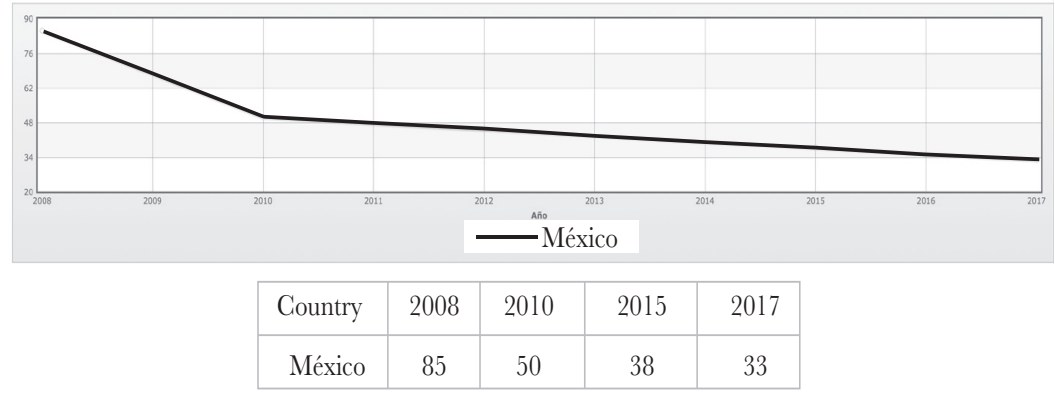

Definición de Tasa de mortalidad materna: La tasa de mortalidad materna (MMRatio) es el número anual de muertes femeninas por cada 100,000 nacidos vivos por cualquier causa relacionada con o agravada por el embarazo o su manejo (excluyendo causas accidentales o incidentales). El MMRatio incluye las muertes durante el embarazo, el parto o dentro de los 42 días de la interrupción del embarazo, independientemente de la duración y el lugar del embarazo, durante un año específico.

FUENTE: Cia. Word Fakbook. A menos que sea indicado, toda la información en esta página es correcta hasta enero de 2018

La evolución a lo largo del tiempo demuestra una tendencia a la baja muy paulatina (figura 2). Los esfuerzos se han centrado en garantizar el acceso universal a la emergencia obstétrica en vista de que el retraso en dicha atención condiciona situaciones que pueden provocar la muerte de la mujer; pero en ese punto también hemos luchado a contracorriente dadas las condiciones de fragmentación de la atención médica en México. La primigenia institución de atención médica, el Instituto Mexicano del Seguro Social, tiene entre sus condiciones contractuales, la obligación de atender únicamente a quienes aportan recursos para su operación de tal forma que solamente atienden a mujeres embarazadas afiliadas a ese sistema. Las demás instituciones presentan condiciones parecidas, incluyendo al llamado "Instituto de Salud para el Bienestar" (INSABI), antes conocido como Seguro Popular, cuya noble intención es brindarle atención médica a la población desprotegida por las demás instituciones. Diseñaron para eso un mecanismo de afiliación inmediato, muy eficiente, pero en vista de que descansa sobre los sistemas hospitalarios estatales (frecuentemente muy desorganizados), no ha producido los deseados beneficios en términos de que cualquier ciudadano o ciudadana mexicana pueda acceder a servicios médicos de calidad en cualquier momento. El problema por supuesto no es simple, pero definitivamente urge retomar el camino hacia la unificación de todas las instituciones federales en una sola gran 
Este libro forma parte del acervo de la Biblioteca Jurídica Virtual del Instituto de Investigaciones Jurídicas de la UNAM

organización que le brinde atención médica al total de la población. Sin ese supuesto será muy difícil continuar disminuyendo de forma significativa la muerte materna.

Además debo mencionar que la salud materna inicia desde antes de la gestación; es decir, una mujer, en el escenario ideal debe decidir, con todos los elementos de juicio, el momento ideal desde su perspectiva para tener descendencia, e idealmente también, corregir previamente todos los factores que pudieran entorpecer o complicar un embarazo. En México estamos el día de hoy muy lejos de lograr esas condiciones. El embarazo no planeado ronda quizá entre el 80 al 90\% de todas las gestaciones aunque las cifras oficiales reportan el 55\% (Juárez et al. 2013), lo que condiciona por si mismo un escenario no favorable. Otro factor que influye en la salud materna y en la muerte son las enormes cifras de embarazo adolescente, que francamente no debería existir, y en caso de que ocurra por alguna falla de un método anticonceptivo, esas niñas deberían tener garantizado el acceso al aborto de forma temprana y eficaz. Nada se cumple hoy en México. Muy pocas mujeres tienen más de cinco consultas prenatales con los tres estudios de ultrasonido recomendados internacionalmente (SS, 2019); el cuerpo médico desconoce los antecedentes de problemas de salud o condiciones bajo las cuales ocurrió la gestación y el colmo es que carecemos de un sistema de expediente médico electrónico que permita acceder a la información previa de cualquier mujer embarazada que acuda con urgencia a un servicio de salud. Adicionalmente son pocas las unidades obstétricas con capacidad para vigilar embarazos con riesgo elevado, como tendrían que ser atendidas el total de las mujeres con diabetes gestacional, es decir más de 100 mil mujeres por año; solo con esa patología.

\section{CRISIS DEL GOVID-19 EN EL EMBARAZO}

La pandemia inició aparentemente en una provincia China, extendiéndose rápidamente por la región y posteriormente en el orbe. Desde el inicio pudimos apreciar que si bien las personas mayores son las que con mayor frecuencia presentan complicaciones; la ciencia carece de elementos para entender el comportamiento de este nuevo virus. Intentando preveer el posible pronóstico, los epidemiólogos en el orbe basaron sus primeras hipótesis en epidemias anteriores causadas por virus parecidos, como el causante del SARS, que inició también en China y se desplegó por diversos países asiáticos. Al final se concluyó una tasa de mortalidad de dicha enfermedad alrededor del 
Este libro forma parte del acervo de la Biblioteca Jurídica Virtual del Instituto de Investigaciones Jurídicas de la UNAM

18\% (Simsek et al., 2020). Especialmente las mujeres gestantes, resultaron en aquella época particularmente susceptibles a complicarse y morir, sobre todo en las fases avanzadas del embarazo. El actual germen es también un coronavirus, parecido al de aquella epidemia; que finalmente se controló y limitó por medidas de distanciamiento social, seguimiento de contactos, aislamiento y cuarentenas, pero nunca se encontraron fármacos eficaces contra la infección y no se desarrolló vacuna. No hubo inversión pública ni privada para asumir dicha responsabilidad.

En épocas más recientes, en el 2009 la humanidad atestiguó la pandemia de influenza $\mathrm{H} 5 \mathrm{~N} 1$, cuyo causante es también un virus respiratorio causante de una "gripe" parecida a la común, pero también con posibilidades de complicar seriamente la salud, en aquella ocasión de personas jóvenes. En aquella época se pudo apreciar también un peligro inminente para las mujeres gestantes, especialmente poco antes del nacimiento. Las medidas de distanciamiento social pudieron limitar rápidamente la propagación de la enfermedad así como el uso temprano del fármaco osteltamivir, que sabíamos es eficaz contra casi todas las variedades. En virtud de que ya se contaba con una vacuna eficaz contra otras variantes del mismo virus, rápidamente los laboratorios pudieron elaborar una contra aquel germen. El número de mujeres embarazadas muertas en México atribuible al virus de la influenza H1N1 en el 2009 fue alrededor de las 250, lo que trastornó la razón de muerte materna que presentaba una ligera cifra a la baja comparada con el año previo.

Con el actual coronavirus SARS-GoV-2, desde el inicio de la declaración de la pandemia en diciembre del 2019, todos los que trabajamos en temas de salud materna, hemos estado pendientes de las cifras publicadas por los diferentes países en relación con la gestación y los reportes han sido francamente escasos. Los investigadores chinos, a la fecha del presente texto, han reportado cifras muy bajas de mujeres gestantes fallecidas por la infección, y señalan que son parecidas a la misma población de mujeres sin embarazo, es decir, la imagen inicial daba la impresión de bajo peligro para la mujer gestante. La mayor cifra de fallecimientos del actual virus, como ya señalé, se centra en personas adultas mayores y las mujeres en edad fértil se ubican en grupos etarios menores. La alarma mundial se despertó por un aparente caso de trasmisión de la madre al feto poco antes del nacimiento (Chi et al., 2020); pero tampoco se ha documentado daño fetal como malformaciones. El caso fue muy cuestionado por el concierto de los países afiliados a la Organización Mundial de la Salud porque no estuvo suficientemente sustentado; así que prevaleció la duda, pero puso en evidencia otra 
Este libro forma parte del acervo de la Biblioteca Jurídica Virtual del Instituto de Investigaciones Jurídicas de la UNAM

vez, lo poco que conocemos del virus. Al momento actual parece haberse descartado la trasmisión vertical, todos los casos estudiados han fracasado en la demostración inequívoca de ese mecanismo de infección. El panorama europeo respecto del curso de la gestación concomitante a la infección, muestra una leve tendencia hacia arriba en los requerimentos de salas de terapia intensiva; es decir que las mujeres embarazadas parecen ser un poco más susceptibles para presentar neumonías graves que requieren intubar a la mujer, comparadas con el mismo grupo etario sin embarazo; pero en cuanto a mortalidad, no existe documentada diferencia importante (Zaigham y Andersson, 2020). Las cifras en Estados Unidos parecen similares (CDC, 2020), por lo que los cuerpos colegiados de profesionales de la obstetricia recomiendan una vigilancia estrecha y el establecimiento de medidas efectivas de telemedicina para que las mujeres puedan estar en contacto continuo con el equipo de salud y en caso de requerirse una evaluación urgente, se pueda articular en una sala de emergencia obstétrica sin dilaciones. Implica esta estrategia, comunicación bidireccional continua, en tiempo real entre las mujeres y los servicios obstétricos.

El panorama descrito brindaba cierta tranquilidad porque esperábamos, por ejemplo en México, cifras prácticamente sin cambio en mortalidad materna y la terrible sorpresa es que al momento en el que escribo estas líneas llevamos más de 100 mujeres que han fallecido embarazadas a causa de la enfermedad COVID-19 de acuerdo a las cifras oficiales, tomadas de los registros de defunción (CONAVE, 2020). En Estados Unidos, con mucho más casos se reportan 39 fallecimientos de mujeres gestantes al momento en el que escribo estas líneas (Metz et al., 2020). Recientemente la Organización Panamericana de la Salud publicó una alerta epidemiológica relativa al COVID-19 durante el embarazo (OPS, 2020) en la que señala claramente las diferencias entre los países latinoamericanos y Estados Unidos. En una primera mirada apreciamos una mucho mayor cantidad de muertes por COVID-19 en Brasil y en México, comparados con los datos estadounidenses, que tampoco resulta congruente al analizar el número de casos totales: 
Este libro forma parte del acervo de la Biblioteca Jurídica Virtual del Instituto de Investigaciones Jurídicas de la UNAM

Tabla 1. Casos y defunciones de Embarazadas CON GOVID-19, SEGÚN PAÍS. REGIÓN AMÉRICA.

1o. DE ENERO DE 2020 AL 11 DE AGOSTO DE 2020.

EMBARAZADAS GON GOVID-19

\begin{tabular}{|l|r|r|}
\hline \multicolumn{1}{|c|}{ País } & Vivas & Fallecidas \\
\hline Argentina & 155 & 1 \\
\hline Bolivia & 50 & 5 \\
\hline Brasil & 2,256 & 135 \\
\hline Colombia & 571 & 2 \\
\hline Ecuador & 849 & 20 \\
\hline Estados Unidos & 15,735 & 37 \\
\hline Haití & 39 & 2 \\
\hline México* & 3,916 & 106 \\
\hline Perú & 4,782 & 36 \\
\hline República Dominicana & 304 & 12 \\
\hline
\end{tabular}

* México notifica embarazadas y puérperas.

Fuentes: Centro Latinoamericano de Perinatología/Salud de la Mujer, y Reproductiva (CLAP/AMR). Información publicada en los sitios de web de los Ministerios de la Salud, Agencias dde Salud o similares y reproducidos por OPS/OMS.

Como se aprecia en la Tabla 1 de dicho documento, Estados Unidos reporta un total de 15,735 mujeres vivas, gestantes infectadas por COVID-19 con 37 fallecimientos, mientras que México señala 3,916 mujeres sobrevivientes con 106 muertes maternas. Parece por completo desproporcionado, aunque debemos mencionar que el método centinela de vigilancia utilizado por México podría dejar de lado muchas mujeres embarazadas que cursan con el cuadro asintomático o con síntomas leves, no es explicación suficiente para la enorme diferencia. Lo mismo ocurren con Brasil y otros países latinoamericanos, inclusive comparados entre si. Por supuesto coincido con la necesidad de emitir una alerta por los organismos internacionales porque los datos son efectivamente alarmantes, pero quizá no se trata de que el virus presente un comportamiento necesariamente mortal en las mujeres embarazadas. Los datos norteamericanos ponen en evidencia una mayor tendencia a presentar formas severas de la enfermedad COVID-19 en el embarazo, de tal forma que aparentemente existe una proporción incre- 
Este libro forma parte del acervo de la Biblioteca Jurídica Virtual del Instituto de Investigaciones Jurídicas de la UNAM

mentada de mujeres gestantes en las salas de terapia intensiva, comparadas con mujeres de la misma edad y condiciones, no embarazadas. Es decir, que a pesar de que no se encuentra incrementada la mortalidad, si hay una la tendencia a presentar cuadros más graves, y aquí pongo el énfasis para señalar que quizá en América Latina no estamos brindando atención rápida y eficiente para detectar a las mujeres embarazadas con COVID-19 que se están agravando. Como en cualquier otro padecimiento infeccioso severo, si no brindamos atención rápida y eficiente, con todos los recursos necesarios, incluyendo unidades de terapia intensiva, la vida de la paciente se ve en peligro inminente. En nuestra zona latinoamericana no hemos progresado en la telemedicina ni en la atención y comunicación en tiempo real con las mujeres embarazadas, hecho que en Europa o EUA constituye el día de hoy parte de los estándares regulares; y ha representado una ventaja durante la pandemia que nos obliga a modificar la atención prenatal en consulta externa. Tampoco hemos hecho ningún progreso sustantivo en la comunicación entre las unidades hospitalarias del fragmentado sistema sanitario, lo que por supuesto entorpece la atención obstétrica regular. Lo anterior solo representa una deficiencia organizacional en virtud de que muchas mujeres embarazadas de todos los estratos sociales tienen hoy, en México, un teléfono móvil que fácilmente podría ser una forma de comunicación rápida y expedita con las unidades de atención obstétrica, aunque dicho teléfono no contara con servicio web, que la mayoría lo tiene. Como país se está articulando, desde hace más de diez años, una estrategia para comunicar mediante medios digitales a segmentos cada día más amplios de la población, incluyendo a los segmentos más aislados y desfavorecidos de la población nacional. Es lamentable la carencia de una aplicación simple que permita y favorezca ese canal de comunicación. Adicionalmente se requiere de un centro de inteligencia de atención obstétrica, de alcance nacional, con capacidad para visualizar la ocupación y disponibilidad de camas en cada unidad sanitaria de atención obstétrica para ponderar y planear tanto la atención regular como la de emergencia. La mayoría de los elementos necesarios para la articulación de la estrategia, existen ya a la mano. Los hospitales tienen acceso web y computadoras con capacidad para albergar una base de datos que alimentaría al centro nacional. Sistemas de comunicación telefónica obviamente también existen. Solo hacen faltan la voluntad política y las decisiones pertinentes. Por supuesto habría que revivir el convenio interinstitucional para la atención de la emergencia obstétrica, con las necesarias vigilancia y supervisión de la operación. En el marco de la pandemia, se tomaron decisiones adecuadas y proporcionales desde el ámbito federal 
Este libro forma parte del acervo de la Biblioteca Jurídica Virtual del Instituto de Investigaciones Jurídicas de la UNAM

con la finalidad de asegurar la disponibilidad de unidades y camas de terapia intensiva para cualquier enfermo o enferma de COVID-19, hablando de la población general, y para lograr el objetivo deseado se adaptaron hospitales o áreas específicas de algunos de ellos dotándolos de los elementos indispensables que permitieran la operación bajo esas nuevas condiciones. Lo que resulta difícil de evaluar - por lo menos en este momento- es el impacto que dichos cambios bruscos están causando en la atención regular programada de los nosocomios; por ejemplo, la persona que estaba a la espera de una prótesis de cadera, bajo estas condiciones ignoramos cuando va a ser sometida a la intervención que le permita caminar otra vez; y podría citar una lista interminable de padecimientos cuya atención hoy se encuentra retrasada. En ese gran rubro de "atrasos" se encuentra la atención de la mujer embarazada, pero con la enorme diferencia de que ella en cualquier momento de la gestación ella puede requerir atención de extrema urgencia y la necesidad de recursos médicos sofisticados y quizá muy complejos, que en este momento están disponibles solo parcialmente en el mejor de los casos. Citando como ejemplo, en la Ciudad de México, cada hospital de alta especialidad con atención obstétrica, quedó clasificado de manera diferente. Existen seis con múltiples especialidades entre las cuales se cuenta la atención de partos, clasificados como "hospitales COVID" y por lo menos otros seis que son "no COVID" como el Instituto Nacional de Perinatología. En el ánimo de conservar la estrategia y la distinción de las unidades, al arranque de la división citada, los hospitales comenzaron a enviar a las mujeres de acuerdo a su condición infecciosa; lo que significa incrementar el riesgo por el solo hecho de que ella tendría que acceder a una unidad quizá más lejana, bajo condiciones de desconocimiento del personal médico respecto al caso concreto. Basta imaginar a una mujer portadora de diabetes gestacional, con 30 semanas de embarazo y datos sugestivos de la infección viral. $\mathrm{El}$ solo hecho de los traslados de un nosocomio al otro, arribando a uno nuevo donde ella desconoce el funcionamiento, implica pérdidas de tiempo que potencialmente son peligrosas bajo algunas circunstancias. Quizá la desarticulación y falta de previsión respecto a la atención regular de mujeres con enfermedades concomitantes, o las que presentan complicaciones a pesar de haber sido sanas previamente, influye negativamente en la calidad de la atención hasta el punto en el que provoca la pérdida de la vida. Partiendo de las cifras europeas y norteamericanas, que ponen de relieve una mayor necesidad de atender a este grupo de mujeres en unidades de cuidados intensivos; con resultados positivos en términos de rescatarlas, acá en México hemos visto el efecto contrario. Lo más probable es que no están llegando 
Este libro forma parte del acervo de la Biblioteca Jurídica Virtual del Instituto de Investigaciones Jurídicas de la UNAM

a tiempo a esas unidades. Eso explicaría la proporción incrementada en mortalidad materna.

\section{EFECTOS EN EL FETO Y RECIÉN NACIDO DEL SARS-GOV-2}

Desde el inicio de la epidemia, otra de las preocupaciones de la comunidad internacional ha sido el paso del virus a través de la placenta. El embrión-feto, se encuentra protegido y aislado del medio ambiente, dentro del organismo materno, manteniendo una barrera que se llama placenta, dejando pasar solamente moléculas como el oxígeno y los nutrientes que le provee la mujer. De forma regular la mayoría de las bacterias son incapaces de franquear la barrera de la placenta, impidiendo así la infección del feto. Los virus al ser partículas mucho más pequeñas, frecuentemente tienen la capacidad de pasar e infectar al feto, ocasionalmente con efectos catastróficos. Tenemos en la historia reciente de las epidemias, el ejemplo del virus causante del Zika, cuyos efectos en el sistema nervioso central del feto pueden ser de extrema gravedad. El virus actual es nuevo por lo que carecíamos de información respecto del asunto, y las experiencias iniciales parecían demostrar que no existe la infección fetal ni malformaciones. La sorpresa ocurrió cuando un investigador en China afirmó que tenía un caso de infección congénita (Peng et al., 2020); es decir el caso de un recién nacido en el que se aisló el germen a las pocas horas del nacimiento. Al investigar el caso de forma pormenorizada surgieron las dudas en el sentido de que el recién nacido se pudo infectar después del nacimiento. La duda ha persistido en el tiempo y se han podido demostrar un par de casos de trasmisión al feto, sin aparentes consecuencias a la salud del recién nacido. Por otro lado existen varios grupos de investigación, incluyendo a uno mexicano en el Instituto Nacional de Perinatología, que están demostrando la existencia de partículas virales en la placenta, lo que sugiere y sostiene que tiene la capacidad de atravesarla, pero en todo caso, las infecciones neonatales en general, no tienen efectos graves en la salud de los bebés. Tampoco se ha demostrado ni un solo caso de malformaciones asociadas. Entonces la infección congénita no parece constituir un problema de salud pública; al menos con los datos con los que contamos a la fecha.

\section{VACUNA CONTRA EL SARS-COV-2 EN EL EMBARAZO}

Las prisas de la ciencia médica por acceder a una vacuna que proteja contra la infección causante del COVID-19 han provocado que los protocolos para 
Este libro forma parte del acervo de la Biblioteca Jurídica Virtual del Instituto de Investigaciones Jurídicas de la UNAM

demostrar su seguridad y eficacia están dejando de lado a una población que nos preocupa especialmente que es la de mujeres gestantes.

Son hechos conocidos la vulnerabilidad de esta población frente a las epidemias previas, la mortalidad por ejemplo durante la última pandemia de influenza, se vio incrementada sensiblemente en el segundo y tercer trimestre del embarazo y la explicación más plausible, pero de ninguna manera la única, giró en torno a la restricción respiratoria en la mujer gestante en vista del volumen abdominal súbitamente incrementado.

También ocurrió un fenómeno parecido con la epidemia previa por otro coronavirus que fue la del SARS, cobrando la vida de muchas mujeres embarazadas. Los estudios con la actual de COVID-19 parecen demostrar no ser tan agresiva con esta población en general; aunque en México si hemos sido testigos de un incremento en la mortalidad que parece estar relacionada con retardos en la atención médica; no exactamente a la agresividad del germen.

En el resto del mundo se aprecia una mortalidad semejante comparativamente con la población de mujeres de la misma edad, no embarazadas. De cualquier manera se trata de una población a la que se le debe cuidado especial, con estrategias dirigidas a proteger su vida, y por lo tanto deberían estar incluidas en los protocolos de ensayos clínicos de las vacunas; obviamente con precauciones específicas como encontrarse en el segundo o tercer trimestre del embarazo y no presentar enfermedades concomitantes, dentro de un ciertos grupos de edad.

Por supuesto lo más probable es que se podría demostrar su seguridad y esto permitiría contemplarlas dentro de los primeros grupos para recibir el biológico y protegerlas de inmediato.

Urge que los gobiernos, articulen acciones para insistir frente a los laboratorios que están conduciendo los estudios e incluyan de forma urgente a esta población que de otra manera vamos a dejar sin protección de forma por completo injustificada.

Francamente la explicación de esta deficiencia parece ser un asunto discriminatorio por parte de los diseñadores de los estudios clínicos, actitud por completo absurda y anacrónica.

No por tratarse de empresas multinacionales y en extremo poderosas, quiere decir que debemos obedecer ciegamente lo que establezcan como sus políticas internas, el gobierno de México debería estar levantando la voz de forma clara para exigirle a dichas organizaciones que subsanen esta grave deficiencia en el diseño de los estudios.

La agencia reguladora norteamericana de salud (FDA) recientemente emitió un comunicado para que el sistema de salud ofrezca a las mujeres 
Este libro forma parte del acervo de la Biblioteca Jurídica Virtual del Instituto de Investigaciones Jurídicas de la UNAM

gestantes la posibilidad de ser vacunadas y que sean ellas quienes, después de una explicación amplia, decidan si acceder o no al biológico. En pocas palabras están descansando el peso ético de la decisión en las propias mujeres dada la carencia de datos suficientes para establecer por completo la seguridad de la vacuna.

\section{REFLEXIONES FINALES}

La nueva infección que enfrenta la humanidad el día de hoy, pone contra la pared argumentos que sostienen el enfoque actual de la atención a la salud bajo criterios de eficiencia económica hasta un punto en el que las contradicciones son irresolubles. También confrontan a la sociedades occidentales con la muy baja inversión en ciencia básica; en general esa tendencia actual en el sentido de que la ciencia solamente puede ser financiada por la industria, plantea un escenario de cambio en los temas de los científicos, abandonando áreas completas como los mecanismos de infección y los relativos a la explicación y estudio del daño causados por microorganismos en el organismo humano. Tampoco el desarrollo de vacunas ha progresado a la par de otras áreas de la ciencia, y por supuesto queda en evidencia la urgencia de regresar el apoyo a estos temas. El problema sustantivo de los gobiernos es que de inmediato muchos actores van a preguntar acerca del origen de los fondos y el regreso de los mismos. Los gobiernos ya no pueden seguir contemplando impávidos a los actores económicos como los únicos que deciden, deben cambiar de sentido para rescatar al derecho a la salud como uno de los determinantes fundamentales alrededor de los cuales se debe planear y articular las decisiones sustantivas. La salud materna se inscribe como punto toral de demostración de esta perspectiva; requiere decisiones, inversión y una actuación de la sociedad en su conjunto para preservar la vida de todas esas mujeres que hoy, están muriendo.

\section{REFERENCIAS}

CDC, 2020, Data on COVID-19 during Pregnancy: Severity of Maternal Illness, Centers for Disease Control and Prevention, disponible en: https:// wrerre.cdc.gov/coronavirus/2019-ncov/cases-updates/special-populations/pregnancydata-on-covid-19.html. Fecha de acceso: 4 de enero de 2021.

CHI, J. et al., 2020, "Clinical characteristics and outcomes of pregnant women with COVID-19 and the risk of vertical transmission: a systema- 
Este libro forma parte del acervo de la Biblioteca Jurídica Virtual del Instituto de Investigaciones Jurídicas de la UNAM

tic review", Archives of Gynecology and Obstetrics, diciembre 1o., 1-9, DOI: 10.1007/s00404-020-05889-5.

CONAVE, Aviso epidemiológico: COVID-19 durante el embarazo al 17 de agosto de 2020, Centro Nacional de Equidad de Género y Salud Reproductiva-Dirección Nacional de Epidemiología, 17 de agosto, disponible en: https://omm.org.mx/blog/aviso-epidemiologico-covid-19-durante-el-embarazo-al17-de-agosto-de-2020/.

DAINELLI, L. et al., 2018, "Screening and management of gestational diabetes in Mexico: results from a survey of multilocation, multi-health care institution practitioners", Diabetes, Metabolic Syndrome and Obesity: Targets and Therapy 5 vol. 2018:11: 105-116. DOI https://doi.org/10.2147/DMSO.S160658.

JuÁREZ, F. et al., 2020, Embarazo no planeado y aborto inducido en México: causas y consecuencias, Instituto Guttmacher, noviembre de 2013, disponible en: https://wrere.guttmacherorg/es/report/embarazo-no-planeado-y-aborto-inducido-enmexico-causas-y-consecuencias \#.

Metz, T. D. et al., 2020, "Maternal Mortality From Coronavirus Disease 2019 (COVID-19) in the United States", Obstetrics \& Gynecology 136(2): 313-316. DOI: 10.1097/AOG.0000000000004024.

OPS, 2020, Alerta Epidemiológica: COVID-19 durante el embarazo, 13 de agosto de 2020, Organización Panamericana de la Salud, disponible en: https://wrwr.paho.org/es/documentos/alerta-epidemiologica-covid-19-duranteembarazo-13-agosto-2020.

PENG, Z. et al., 2020, "Unlikely SARS-CoV-2 vertical transmission from mother to child: A case report", Fournal of Infection and Public Health 13(5):818820. DOI: 10.1016/j.jiph.2020.04.004.

SiMSEK, Y. et al., 2020, "Maternal and fetal outcomes of COVID-19, SARS, and MERS: a narrative review on the current knowledge", European Review of Medical and Pharmacological Sciences, vol. 24, núm. 18: 9748-9752. DOI: 10.26355/eurrev_202009_23068.

SS, 2019, Boletín Epidemiológico Sistema Nacional de Vigilancia Epidemiológica Sistema Único de Información, vol. 36, núm. 30, Secretaría de Salud, disponible en: https://wrere.gob.mx/cms/uploads/attachment/file/483154/ sem30.pdf.

WeBSTER, R. G., 2018, Flu Hunter: Unlocking the secrets of a virus, Otago University Press, disponible en: https://b-ok.lat/book/5007921/919e2b.

Wikipedia, 2020, Anexo: Tasa de mortalidad de enfermedades humanas, disponible en: https://es.wikipedia.org/wiki/Anexo:Tasa_de_mortalidad_de_enfermedades_humanas. Fecha de acceso: 4 de enero de 2021. 
Este libro forma parte del acervo de la Biblioteca Jurídica Virtual del Instituto de Investigaciones Jurídicas de la UNAM

Zaigham, M. y Andersson, O., 2020, "Maternal and perinatal outcomes with COVID-19: A systematic review of 108 pregnancies", Acta Obstetricia et Gynecologica Scandinavica 99(7): 823-829, disponible en: https://doi. org/10.1111/aogs. 13867 . 